\title{
Instructional Design Framework for Construction Materials Training
}

\author{
Hazem Jadallah ${ }^{1 *}$, Carol J. Friedland ${ }^{1}$, Isabelina Nahmens ${ }^{2}$, Charles Pecquet ${ }^{1}$, \\ Charles Berryman ${ }^{1}$ and Yimin Zhu ${ }^{1}$ \\ ${ }^{1}$ Bert S. Turner Department of Construction Management, Louisiana State University, Baton Rouge, LA, United States, \\ ${ }^{2}$ Department of Mechanical and Industrial Engineering, Louisiana State University, Baton Rouge, LA, United States
}

OPEN ACCESS

Edited by:

Rahul V. Ralegaonkar, Visvesvaraya National Institute of Technology (VNIT), Nagpur, India

Reviewed by:

Syaamantak Das,

Indian Institute of Technology Kharagpur, India

Sayyad Zahid Qamar,

Sultan Qaboos University, Oman

*Correspondence:

Hazem Jadallah hazem426@gmail.com

Specialty section: This article was submitted to Construction Materials,

a section of the journal Frontiers in Built Environment

Received: 20 October 2021 Accepted: 07 December 2021

Published: 10 January 2022

Citation:

Jadallah H, Friedland CJ, Nahmens I, Pecquet $C$, Berryman $C$ and Zhu $Y$ (2022) Instructional Design Framework

for Construction Materials Training.

Front. Built Environ. 7:798843. doi: 10.3389/fbuil.2021.798843
The construction industry is suffering, in part, from a lack of training programs offered to the construction workforce. Unfortunately, most construction training and education research focuses on university student education. Integrating education science theory into construction workforce training has the potential to improve industry training but there is a dearth of studies that present details of this integration process. To address this gap, a training framework was developed to educate material stakeholders on material properties, selection, and installation. This framework is based on andragogical and Universal Design for Learning (UDL) principles. An assessment method evaluates training agendas to improve upon instructional design before training implementation. This method assesses the proposed training framework by enumerating the occurrences of Bloom's Taxonomy verbs to determine how closely the proposed training's goals and objectives followed Bloom's guidelines. This study culminates by establishing linkages from educational theory to proposed training modules. The module template is presented in a goals and objectives format so that organizations can best implement and test this training framework.

Keywords: andragogy, universal design for learning, construction, training, materials, instructional design

\section{INTRODUCTION}

Construction plays a major role in the global economic development (Hosseinian and Jabbarani 2012). Construction defects often result from the absence of an installation methodology or lack of knowledge of proper installation (Forcada et al., 2014) leading to a material or system failure even if the proper material is selected (Tatum 2011). Given the dependence of project outcomes on skilled labor, quality material installation and effective selection are paramount (Mills et al., 2009). Lack of technical knowledge, training, and experienced skilled labor and supervision, along with procedure non-compliance, have been identified as causative factors for $13 \%$ of total construction field rework costs in the U.S. (Karimi et al., 2018). The potential loss of life from material, system, and structural failures, along with the significant financial losses from unnecessary rework, warrant the establishment of educational theory-integrated training programs that focus on construction materials.

It is well known that there is a global unmet need for construction industry training (Russell et al., 2007; Killingsworth and Grosskopf 2013). Existing training resources include project personnel, professional publications, textbooks, and technical information from equipment manufacturers and materials suppliers; however, there is little to no standardization in construction industry training and it is not uniformly available in the broader industry landscape outside of traditional education (Tatum 2018). Studies that come close to addressing this gap, such as the framework design example by Joo Hyoung 
et al. (2008) that assesses student response to learning theory, are tailored specifically to civil engineering students rather than skilled industry applicators. These assessments and studies demonstrate the gap in training dedicated to the construction industry workforce and further highlight the gap in training specific to the field of construction materials.

A literature search reveals few published educational-theory embedded training studies dedicated in part to construction workers; however, when they do exist, these studies focus primarily on safety training. For example, Bena et al. (2009) offered 4-h safety training modules for construction workers on a high-speed railway line project in Italy. This study cited andragogy, the study of facilitating adult learning, in contrast to pedagogy, the study of facilitating child learning (Knowles 1980), as the inspiration for the training curriculum. Andragogical specialists developed safety training designed for construction contractors in a study described by Eggerth et al. (2018). Lin et al. (2018) used computer-based visualization, designed by adult education experts, to train construction workers on safety and fall fatalities. These studies demonstrate few instances of andragogy-embedded training programs dedicated to construction worker safety, however, a major shortcoming within existing literature is a lack of training focusing on detailed construction means and methods. This gap also extends to educational theory-embedded training programs dedicated to construction materials.

It is common in several professional industries to apply formal educational theory to ongoing professional training. For example, Gaikwad and Bharathi (2018) apply formal educational principles to training in the field of information technology as a means of teaching artificial intelligence. Antonis et al. (2011) apply similar theories to web-based computer science training as a solution to overcoming educational barriers associated with standardized education. Ecological training programs have taken place using andragogical principles to teach participants how to investigate wildland fire behavior (Parkinson et al., 2003). Chunlin (2017) found an improvement in English language education amongst Chinese adults after the implementation of andragogical theory into a teaching framework. Andragogy was used in police training framework formulation to improve upon more traditional methodologies that were found to have limited effectiveness (Michael 2003). Given the breadth of disciplines and prior competency demonstrated by these examples, it is reasonable to expect that similar opportunities in the construction industry exist and it is possible that they be applied to construction material applicator training.

In addition to offering training, it is important to acknowledge that learners have different needs, and increasing flexibility in learning is crucial (Nikolova and Collis 1998). Universal Design for Learning (UDL) was designed by the Center for Applied Special Technology (CAST) to address this concern. UDL was designed to incorporate adaptable instructional materials and techniques to satisfy a wide range of learning styles is UDL (Orkwis 2003). This method presents the idea that educational support should be embedded in educational frameworks as opposed to introducing modifications haphazardly (Hitchcock 2001). Because flexibility is incorporated into the design of UDL, it has the ability to evaluate subject, without instituting barriers that could have a negative bias towards participants such as question interpretation, phrasing, and assessment flexibility (Rose and Dolan 2000).

The overall goal of this study is to address the need for optimal construction industry training through the embedment of educational theory by creating a field application training framework developed to educate material installers on material properties, selection, and installation. This framework is designed to target current industry professionals that lack significant experience and require an introductory level training. It is based on andragogical and UDL principles; which were chosen because they accommodate adults and flexible education, respectively. This study also addresses the gap in construction industry training programs by proposing a detailed instructional design style format that can be replicated and tested by construction material manufacturers. While there may be an initial cost to institute such a program, training should be implemented for construction stakeholders on how to properly select and install construction materials because improper material selection and installation adversely affect sustainability of infrastructure and lead to project failures; which lead to greater cost in the long term.

Recent research by the authors found that there is a dearth of construction industry training programs in archival literature (Jadallah et al., 2021a); and opportunities exist to implement training programs coupled with optimal assessment methodologies grounded in established educational assessment research (Jadallah et al., 2021b). This study builds upon these findings by creating a process specific to construction materials for developing a construction training framework, as well as the developed framework. The framework is broken into modules that a wide variety of construction material manufacturers are able to implement, and each module is linked to appropriate andragogical, UDL principles, Bloom's Taxonomy terminology, and 70:20:10 principles. The assessment method contributes by providing a method of evaluating similar training agendas to improve upon instructional design before training implementations. A major issue for construction education is the lack of concentration of ongoing training for industry professionals (Mohamad et al., 2015). This research looks beyond formal education tailored to undergraduate or graduate students and focuses on active construction industry participants. This research further contributes by its focus on construction materials whereas previous research focuses on the broader construction craft training or construction equipment handling.

\section{METHODOLOGY}

To create the framework, the core principles of Bloom's Taxonomy, the 70:20:10 principle, andragogy, and UDL were elicited and the general learning outcomes were identified and mapped to these principles. Global student outcomes were identified, which are general for materials training. An assessment method evaluating the effectiveness of this training framework is presented by quantifying the verbs associated with 
the categories of Bloom's Taxonomy to address weaknesses found when generating similar training frameworks.

Bloom's Taxonomy is a sequential or hierarchical process. The theory is that one cannot understand concepts without first remembering them for example. These categories are broken into lower-order thinking skills (LOTS) and higher-order thinking skills (HOTS); with LOTS composed of remember, understand, and apply, and HOTS composed of analysis, evaluate, and create (Churches 2008). If the assumption is that the target audience has had exposure to the topic, higher-order levels of Bloom's Taxonomy should be the focus. If the assumption is the opposite, lower-order levels should be the focus. Absolute and relative frequencies of LOTS and HOTS that occur in the framework are quantified.

\section{Framework Construction}

The developed training framework is composed of a series of modules that may be applied to virtually any construction product portfolio and this paper discusses the general philosophies and methodologies applied. This framework was designed assuming that participants have limited exposure to the subject matter. This assumption encouraged the insertion of scaffolding into the framework. Scaffolding is a term used in education to illustrate temporary support that instructors provide to learners, until they are able to complete tasks alone (Hammond 2001). This metaphor, first used by Wood et al. (1976), was taken from scaffolding used to support builders until a building can stand on its own, and the scaffolding can be removed. This theory manifests itself in the framework by including the instructor in all demonstrations and applications, as well as through an emphasis on groupmates that individuals can use for support. This ensures that participants will have someone to walk through steps and discuss processes with.

The stated goals of each module are also based on the goal setting theory of (Locke and Latham 2002), who suggest that effective objectives are those that select a specific intent, have clear action plans, and are challenging. This theory is commonly regarded as the impetus for the commonly used SMART acronym (Specific, Measurable, Action-oriented, Realistic, Time-bound) (Rowe et al., 2017).

The primary philosophy behind this framework is the concept of modern andragogy, which is based on six main assumptions (Merriam et al., 2007):

1. Self-Concept (SC): Adult learners are self-directed, autonomous, and independent.

2. Role of Experience (RE): The repository of an adult's experience is a rich resource for learning. Adults tend to learn by drawing from their previous experiences.

3. Readiness to Learn (RL): Adults tend to be ready to learn what they believe they need to know.

4. Orientation to Learning (OL): Adults learn for immediate applications rather than for future uses. Their learning orientation is problem-centered, task-oriented, and life-focused.

5. Internal Motivation (IM): Adults are more internally motivated than externally motivated.
6. Need to Know (NK): Adults have a need to know the value of learning and why they need to learn.

This framework was also developed to cater to a diverse learner population. This technique for developing curricula that utilizes adaptable instructional materials and techniques to satisfy a wide range of learning styles is UDL (Orkwis 2003). UDL Principles fall into three main categories. These categories are designed to present multiple means of representation, action and expression, and engagement. Each category consists of three levels that provide options to guide the learning process to accommodate a wide crosssection of learners. The Representation category consists of Levels 1-3 which provide options for perception, language, and comprehension, respectively. The Action and Expression category consists of Levels 4-6 which provide options for physical action, expression and communication, and executive functions, respectively. The Engagement category consists of Levels 7-9 which provide options for recruiting interest, sustaining effort and persistence, and self-regulations, respectively.

The framework discussed in this paper is further inspired by the findings of (McCall et al., 1988) on the source of executive management development, where $70 \%$ is derived through challenging assignments (experiential), 20\% occurs through developmental relationships (social), and $10 \%$ occurs through formal training and coursework (formal); often referred to as the 70:20:10 philosophy.

The theory in breaking the framework into modules is not only to compartmentalize different lessons in the training, but to also allow participants to take structured breaks in between modules. Small diversions in learning are shown to greatly increase the participant focus (Ariga and Lleras 2011) so that when participants return for the next training module they are refreshed and ready to focus. The module format further eases the task of structuring each module so that it corresponds to the six main assumptions of andragogy.

The topics of each module are developed by identifying the overall training program's important lessons to improve the selection and installation of construction materials which are then distributed in a manner which fits the 70:20:10 philosophy while adhering to Bloom's Taxonomy, andragogical principles, and presented to instructors using the UDL format. The subject of each module was determined by a comprehensive construction education literature review that establishes the importance of construction materials education. This review found the following information, which influenced the subject of each module in the training framework:

- It is necessary to obtain knowledge of design properties such as chemical components of materials to solve and avoid issues in the field (Tatum 2011).

- Engineers may not always specify detailed material properties in design, giving applicators a wide range of materials to choose from that fall into a single portfolio (Tinotenda Fredrick 2019).

- Construction material selection is one of the most significant responsibilities of construction professionals 
because it directly correlates with project performance (Mehmood et al., 2018).

- High turnovers in the construction industry have resulted in the current construction workforce possessing only baseline installation experience ( $\mathrm{Li}$ et al., 2015).

- Learning construction through experience-based scenarios has the potential to be appealing to adults as well as increasing the potential performance of entire groups (Goulding et al., 2012).

- Construction quality control measures and troubleshooting should be emphasized due to the difference in the nature of the traditional manufacturing workforce from the construction industry workforce (Arditi and Günaydin 1997).

- Project outcomes are affected due to the lack of assessment of learning major construction tasks (Jarkas 2010).

- Construction material installation methods are to be included in construction specifications (Harris 2006), and there is an increasing demand that specification writing be taught at the undergraduate level (Abudayyeh et al., 2000).

- Research has established the importance of preconstruction meetings, and it is crucial that they are executed properly (Abbas et al., 2016).

In the following section, the connection from each module to the corresponding assumption(s) of andragogy will be evaluated. These connections are further explained in the framework table shown in the results section, emphasizing the linkages between the module construct and andragogical assumptions. This table also links the modules to UDL assessments so that training participants are assessed in terms of knowledge that they have acquired throughout the course of a training program. Applying UDL to workforce training programs will broaden participation in these programs because it was developed to focus on groups of learners, and does not follow a one size fits all methodology (Johnston and Castine 2019). The target audience is the broader construction workforce that is comprised of adults. For this reason, the theory of andragogy, which has been studied thoroughly by education experts is applied.

\section{Module 1: Product Chemistry}

The goal of this module is to provide a basic understanding of components for any given construction material and any reactions that may occur during product mixing or installation. Training participants should learn the importance of these components and how ambient conditions influence product reactions, both during installation and in service.

Under the 70:20:10 philosophy, this module is classified as standard coursework, because this is information that must be formally taught and memorized. Bloom's Taxonomy terms such as "identify" and "discuss" in the "Remember" and "Understand" categories, respectively appear most frequently in the goals and objectives, denoting the necessity to remember and understand the information presented. The UDL principles noted are designed to provide options for language and comprehension.

The most important andragogical assumptions to emphasize in structure and delivery are the NK and RE concepts. The importance of chemistry or basic components of a construction material may not seem important during installation at face value to many installers. For this reason, it is important to stress the necessity of gaining this knowledge. Basic chemistry principles such as how materials interact with the environment that they are placed in should be emphasized while explaining which components in the materials interact with various environmental elements. This concept is made more tangible by referencing weather conditions during installation, weather conditions of material storage locations, and substrates on which materials are applied.

The NK component is further emphasized by calling on the participants' experience (RE). A simple example is asking the attendees if they have mixed a cementitious material in temperatures above $90^{\circ} \mathrm{F}$. This should draw on the experience of reduced working time and early cementitious material setting time. Teaching this basic chemistry principle and how it correlates to the materials will have lasting effects if one recalls instances of experiencing the principle in action (Padwa et al., 2019).

\section{Module 2: Understanding Product Portfolio}

It is common for construction material manufacturers to have several products within one portfolio. It is important that when detailed material properties are not specified contractors and applicators are able to select the material best suited to meet the owners' needs as well as to optimize the service life of a material post-installation (Jan et al., 2012).

This module is delivered in person by using a "hands-on" approach. Training participants are taken to a suitable location outside (but ideally nearby) the standard classroom environment where they practice installing the different products that belong to a single portfolio. This allows them to experience the differences in the different products, while at the same time giving the trainer an appreciation for the installation aptitude of each individual.

Under the 70:20:10 philosophy, this module is classified as a challenging assignment, because of the physical and mental components of the module. Bloom's Taxonomy terms such as "identify" and "comprehend" in the "Remember" and "Understand" categories, respectively appear most frequently in the goals and objectives, denoting the necessity to remember and understand the information presented. The UDL principles noted are designed to provide options for language and comprehension.

The main andragogical assumptions correlating to the structure of this module are RE, RL, and IM. It is expected that training participants have at least some experience in applying the materials that correspond to the training that they are attending. While applying these materials it is also expected that they will revert to any experience that they have. This gives the trainer the chance to correct incorrect behavior or techniques and affirm correct behavior and techniques.

Participants of training display a positive view of "hands-on" education (Thorsteinsson and Page 2018). This outlook makes the training attendees ready to learn what they believe is a practical application of content given in the training programs. 
By the same token, training attendees are motived to internalize the information given, due to the nature of delivery. Learners are driven by the knowledge that they feel is practical (Wei and Li 2017).

This module precedes the material selection module because it offers the necessary visualization of product handling and installed conditions; further enabling participants to make educated material selection decisions.

\section{Module 3: Material Selection}

After completing installation of several products within a portfolio, learners should have a basic appreciation for the range of products offered by the manufacturer. This module is designed to further solidify that knowledge, offering more technical information in a traditional classroom environment. Throughout the course of this module, participants should learn to evaluate material performance and application properties and select the proper material for the project requirements. It is possible apply this concept to virtually any construction material by comparing properties within a portfolio by emphasizing their advantages, disadvantages, and how they relate to a specific project function and environment.

Under the 70:20:10 philosophy, this module is classified as a challenging assignment, because of there is a need for critical thinking and proper selection. Bloom's Taxonomy terms such as "use" in the "Apply" category appear most frequently in the goals and objectives, denoting the necessity to utilize information gathered up to this point. The UDL principles noted are designed to provide options for comprehension.

The andragogical assumption associated with this module is the NK concept. The opportunity should be taken in this module to highlight that while products belong in the same portfolio, and in many instances are comparable or interchangeable, there are differences in installation or material properties and performances.

\section{Module 4: Installation Techniques}

The purpose of this module is to provide participants with an understanding of how to properly install materials. The module should incorporate best practices for safety, choosing the proper equipment to aid in the installation of materials, and using the best methods to achieve a successful installation. A "hands-on" demonstration will provide the participants with the chance to install construction materials using the recommended technique by the manufacturer. The participants will observe and then demonstrate the use of proper equipment use and product installation techniques.

Under the 70:20:10 philosophy, this module is classified as a challenging assignment, because of the physical and mental components of the module. Bloom's Taxonomy terms such as "identify" and "use" in the "Remember" and "Apply" categories, respectively appear most frequently in the goals and objectives, denoting the necessity to remember and apply the information gathered. The UDL principles noted are designed to provide options for comprehension, expression, and communication.

The main andragogical assumptions are SL and OL. After observing the trainer apply materials with proper technique, participants are asked to do the same. During this exercise a sense of independence is present due to the activity's nature. Each participant must learn the nuances of installation for himself or herself only after observation and slight direction from the training instructor.

The OL concept is attributed to this module because the immediate application to this knowledge becomes apparent. Participants should understand that at the conclusion of this training they will be required to apply the materials that they have been trained to install in real life situations on actual construction projects. This application is often immediate creating a sense of urgency to retain the information given.

\section{Module 5: Group Scenario Activity}

The purpose of this activity is to provide the participants with the opportunity to use the information learned in the previous modules, to create a solution for a construction project pertaining to the materials that have been covered in the training to this point. Given a scenario with project condition information including substrate, environmental conditions, project needs, and photo documentation, the participants will work in groups to provide the information requested of their group.

Under the 70:20:10 philosophy, this module is classified as a social interaction, because of the group assignment associated with the module. Bloom's Taxonomy terms such as "select" and "show" in the "Remember" and "Apply" categories, respectively appear most frequently in the goals and objectives, denoting the necessity to remember and apply the information gathered. The UDL principles noted are designed to provide options for comprehension and sustaining effort and persistence.

This module draws on the assumptions of RE, OL, and NK. At this point in the training participants should not only have the experience that they have gained in their respective professional lives, but the experience that they have gained through the previous modules in the training. This module further emphasizes the participants' orientation to learning because it is task-oriented and life-focused. When presented with a real-life scenario they will be asked which products and techniques would suit the scenario best. Because it is a real-life scenario, the need to know assumption is stressed. Participants will realize that these situations occur and that they may be faced with similar scenarios in real-life instances.

\section{Module 6: Troubleshooting}

The goal of this module is to provide the participants with an understanding of common issues related to the materials being discussed in the training. This section identifies the causes of a range of issues related to installation techniques, substrate surface preparation, ambient conditions, and possible existing structure shortcomings. This module also provides an opportunity for participants to learn ASTM methods associated with the materials that they are installing to further expand upon troubleshooting potential issues.

Under the 70:20:10 philosophy, this module is classified as a challenging assignment, because of the physical component of performing ASTM tests and the mental component of understanding and interpreting the results. Bloom's Taxonomy terms such as "identify" and "comprehend" in the "Remember" 
and "Understand" categories, respectively appear most frequently in the goals and objectives, denoting the necessity to remember and understand the information presented. The UDL principles noted are designed to provide options for language, comprehension, expression, and communication.

This module draws upon the assumptions of RE and NK. In this module the instructor should draw on the participant experiences by stating or asking for common issues associated with the training materials (Nuthall and Alton-Lee 1995). Participants will likely have experienced issues if they are truly common, making the material covered in the training much richer. Similarly, the instructor should stress the importance of this knowledge. The concept of troubleshooting often arises when there is a situation in the real world that is not explicitly covered or mentioned in product data guides. Participants should learn common troubleshooting methods associated with the training materials and how they are applied when there is a situation presented that is not the norm or standard.

\section{Module 7: Hands-On Demonstration Assessment}

In Module 4, Installation Techniques, participants observed proper installation technique and then instructed to incorporate this technique in the own installation trials. In this module, the instructor assesses each participant's material installation. The module is separate from the Installation Techniques Module so that materials will have ample time to cure. This may vary depending on the materials used in the training program. Individuals or groups will be asked to discuss the results of ASTM tests that they will have to apply on their installations. These ASTM tests should be covered in Module six and the participants should now be able to interpret the results.

Under the 70:20:10 philosophy, this module is classified as a challenging assignment, because of the material installation and interpretation of results necessary to complete the module. Bloom's Taxonomy terms such as "identify" and "comprehend" in the "Remember" and "Understand" categories, respectively appear most frequently in the goals and objectives, denoting the necessity to remember and understand the information presented. The UDL principles noted are designed to provide options for comprehension and self-regulation.

The main andragogical assumptions correlating to the structure of this module are RE and IM. Participants will draw on their external experience, recalling similar installations as well as their installations completed in Module 4. The experience of installing the material will provide valuable insight into the participants' assessment of their own installation. The concept of internal motivation proves relevant because there is an inherent human psychological desire to defend oneself (Ziębacz and Moraru 2017). Participants are asked to interpret their installations and explain both the positives and negatives. The internal motivation assumption reinforced with the psychological premise of human inherent nature to defend oneself should cause a strong retention.

\section{Module 8: Product Specifications}

Construction specifications detail the work needed to complete a construction project. According to the Dictionary of Architecture
\& Construction a specification (Harris 2006), construction material installation methods are to be included in construction specifications. This module should provide an understanding of material specifications addressed in the training program. Participants will learn how specifications contribute to installation quality and how to interpret specifications that are performance based, where product names are not used but generic product descriptions are given.

Under the 70:20:10 philosophy, this module is classified as a social interaction, because groups will go over the information presented together and present the information to the class. Bloom's Taxonomy terms such as "describe" and "document" in the "Understand" and "Apply" categories, respectively appear most frequently in the goals and objectives, denoting the necessity to comprehend and utilize the information gathered. The UDL principles noted are designed to provide options for language and comprehension.

The primary andragogical assumptions that this module draws upon are RE and RL. The instructor should again correlate the importance of specifications to past experiences that participants may have in interpreting specifications that are left open. The instructor should also revert to Module 2, Understanding the Product Portfolio to highlight differences in the products that either comply with or do not comply with common terminology in specifications associated with the materials.

This module is recommended to be given in a standard classroom environment. The assumption that adults are ready to learn is vital as there is no tangible aspect such as material installation. It is expected that the participants are interested and willing to dedicate the time necessary to learn the material being shared throughout the course of this module.

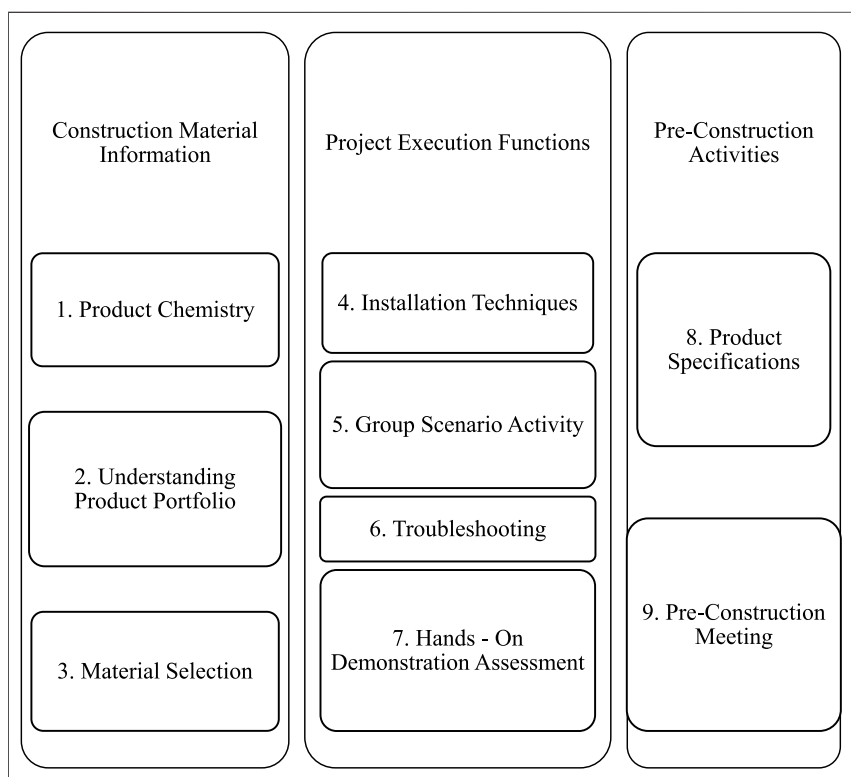

FIGURE 1 | Construction materials training framework lesson segments. 

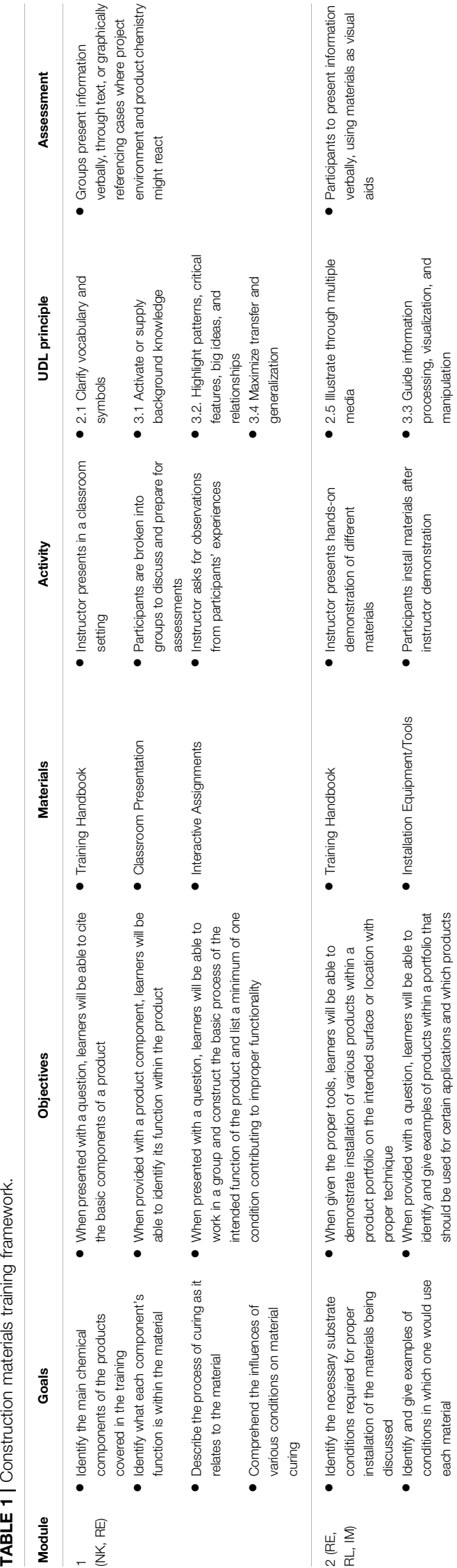
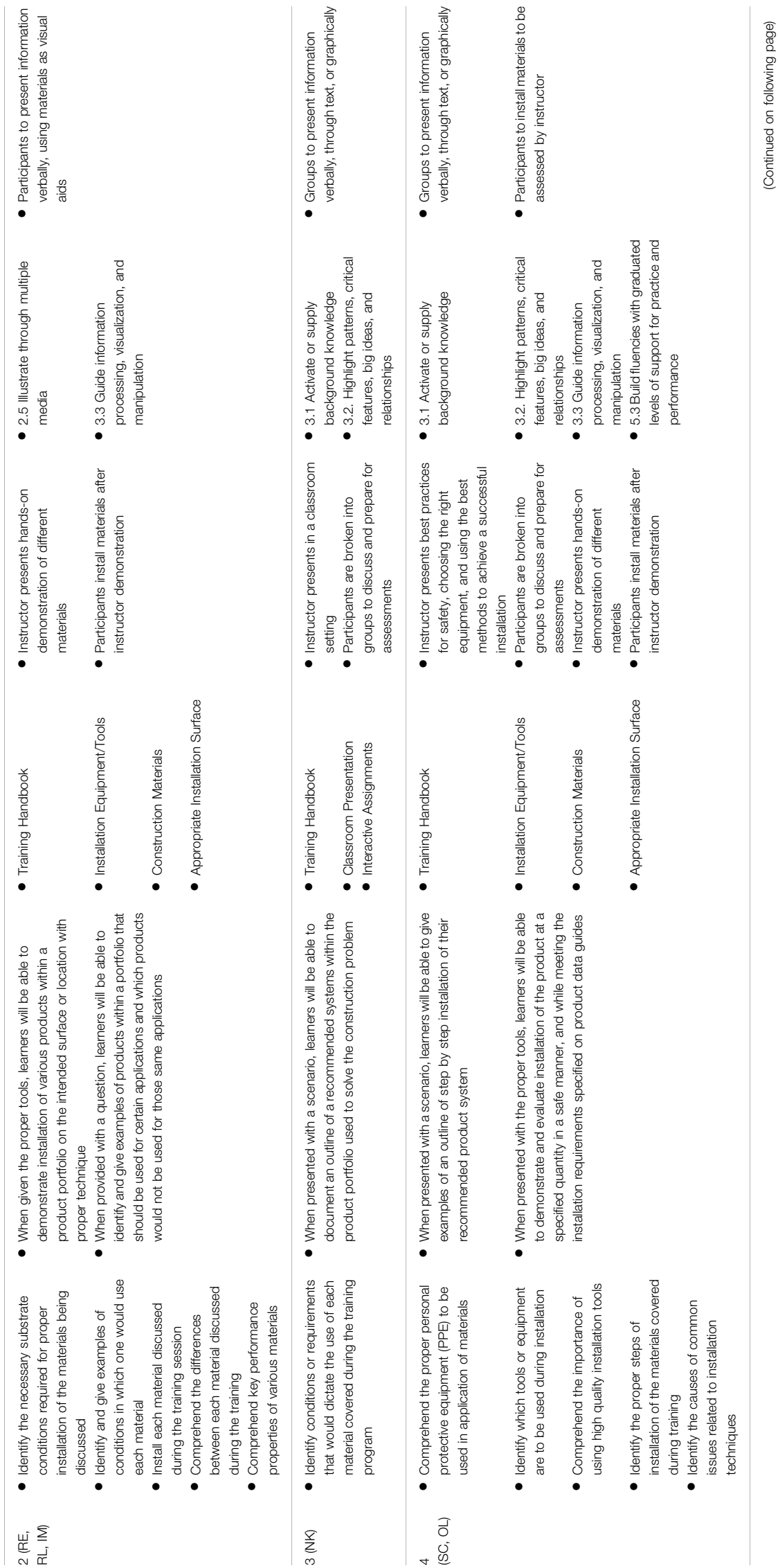
TABLE 1 | (Continued) Construction materials training framework.

\begin{tabular}{|c|c|c|c|c|c|c|}
\hline Module & Goals & Objectives & Materials & Activity & UDL principle & Assessment \\
\hline $\begin{array}{l}5(\mathrm{RE}, \\
\mathrm{OL}, \mathrm{NK})\end{array}$ & $\begin{array}{l}\text { - Work within a group to show the } \\
\text { requested information for their } \\
\text { scenario activity } \\
\text { - Relate the information presented in } \\
\text { previous modules to practice } \\
\text { problem-solving a "real world" } \\
\text { condition } \\
\text { - Show an outline of the groups } \\
\text { suggested recommendations to } \\
\text { the rest of the class and engage in } \\
\text { any proceeding discussions }\end{array}$ & $\begin{array}{l}\text { - When presented with a real-world scenario, learners will be } \\
\text { able to work within a group to select possible causes of the } \\
\text { issues outlined in the activity } \\
\text { - When presented with a real-world scenario, learners will be } \\
\text { able to work within a group to select an outline of the } \\
\text { recommended surface preparation for their project } \\
\text { - When presented with a real-world scenario, learners will be } \\
\text { able to work within a group to select an outline of a } \\
\text { recommended product system used to solve construction } \\
\text { problems } \\
\text { - When presented with a real-world scenario, learners will be } \\
\text { able to work within a group to select an outline of step by } \\
\text { step installation of their recommended product system } \\
\text { - When presented with a real-world scenario, learners will be } \\
\text { able to work within a group to show the information to the } \\
\text { class in a presentation and engage in any proceeding } \\
\text { discussions }\end{array}$ & $\begin{array}{l}\text { - Training Handbook } \\
\text { - Classroom Presentation } \\
\text { - Case Studies }\end{array}$ & $\begin{array}{l}\text { - Instructor presents in a classroom } \\
\text { setting } \\
\text { - Participants are broken into } \\
\text { groups to discuss and prepare for } \\
\text { assessments } \\
\text { - Groups will present to the class }\end{array}$ & $\begin{array}{l}\text { - } 3.1 \text { Activate or supply } \\
\text { background knowledge } \\
\text { - } 8.3 \text { Foster collaboration and } \\
\text { community }\end{array}$ & $\begin{array}{l}\text { - Groups to present information } \\
\text { verbally, through text, or graphically }\end{array}$ \\
\hline $\begin{array}{l}6 \\
(\mathrm{RE}, \mathrm{NK})\end{array}$ & $\begin{array}{l}\text { - Identify causes for complaints } \\
\text { related to improper installation } \\
\text { - Identify causes for common } \\
\text { problems that occur within a } \\
\text { structure } \\
\text { - Comprehend the variations in } \\
\text { onsite conditions that affect } \\
\text { installation technique or } \\
\text { methodology } \\
\text { - Comprehend the importance of site } \\
\text { mock-ups } \\
\text { - Perform ASTM tests associated } \\
\text { with the materials discussed and } \\
\text { comprehend the results }\end{array}$ & $\begin{array}{l}\text { - When give the proper tools, learners will be able to perform } \\
\text { relevant ASTM tests on a previously installed products and } \\
\text { communicate the results to the instructor } \\
\text { - When provided with an example of a specific material failure, } \\
\text { learners will be able to identity potential causes of the issue } \\
\text { - When provided with an example of a specific material failure, } \\
\text { learners will be able to identify and give examples of potential } \\
\text { remedies for the issue }\end{array}$ & $\begin{array}{l}\text { - Training Handbook } \\
\text { - Classroom Presentation } \\
\text { - Case Studies } \\
\text { - Interactive Assignments }\end{array}$ & $\begin{array}{l}\text { - Instructor presents in a classroom } \\
\text { setting } \\
\text { - Participants are broken into } \\
\text { groups to discuss and prepare for } \\
\text { assessments }\end{array}$ & $\begin{array}{l}\text { - } 2.1 \text { Clarify vocabulary and } \\
\text { symbols } \\
\text { - } 3.1 \text { Activate or supply } \\
\text { background knowledge } \\
\text { - } 3.4 \text { Maximize transfer and } \\
\text { generalization } \\
\text { - } 8.3 \text { Foster collaboration and } \\
\text { community }\end{array}$ & $\begin{array}{l}\text { - Groups to present information } \\
\text { verbally, through text, or graphically }\end{array}$ \\
\hline 7 (RE, IM) & $\begin{array}{l}\text { - Convey to the instructor each } \\
\text { material that was installed } \\
\text { - Comprehend why each material } \\
\text { would be used } \\
\text { - Comprehend the quality of each } \\
\text { installation } \\
\text { - Comprehend the results of ASTM } \\
\text { tests conducted on the installations }\end{array}$ & $\begin{array}{l}\text { - When asked questions concerning installations, participants } \\
\text { should be able to } \\
\text { - Identify the product installed in each "mockup" } \\
\text { - Identify and give examples of conditions that would call for } \\
\text { - each material to be used } \\
\text { - Clearly state and evaluate the results of the ASTM tests }\end{array}$ & $\begin{array}{l}\text { - Student application specimen } \\
\text { from Module } 4 \\
\text { - ASTM Standards }\end{array}$ & $\begin{array}{l}\text { - Instructor evokes participant's } \\
\text { self-reported application quality } \\
\text { interpretation and explain positives } \\
\text { and negatives } \\
\text { - Participants conduct ASTM tests }\end{array}$ & $\begin{array}{l}\text { - } 3.1 \text { Activate or supply } \\
\text { background knowledge } \\
\text { - } 3.4 \text { Maximize transfer and } \\
\text { generalization } \\
\text { - 9.3 Develop self-assessment and } \\
\text { reflection }\end{array}$ & $\begin{array}{l}\text { - Instructor to interpret quality of } \\
\text { installation as well as interpret ability } \\
\text { of each participant to conduct } \\
\text { ASTM tests }\end{array}$ \\
\hline $\begin{array}{l}8 \\
(R E, R L)\end{array}$ & $\begin{array}{l}\text { - Identify construction documents } \\
\text { - Comprehend what constitutes a } \\
\text { need for a specification change } \\
\text { - Describe the key components of a } \\
\text { material specification } \\
\text { - Define relevant test standards for } \\
\text { the material discussed } \\
\text { - Comprehend roles and } \\
\text { responsibilities for material } \\
\text { applications }\end{array}$ & $\begin{array}{l}\text { - When presented with a question, learners will be able to } \\
\text { name and give examples of all the various documents that } \\
\text { would be considered "construction documents" } \\
\text { - When presented with a question, learners will be able to } \\
\text { describe the process for change on a construction project } \\
\text { - When presented with a question, learners will be able to } \\
\text { define the key components of a product specification } \\
\text { - When presented with an application, learners will be able to } \\
\text { determine the appropriate test standards for assessing } \\
\text { physical properties } \\
\text { - When presented with a scenario, learners will be able to } \\
\text { describe the various roles and responsibilitilis of } \\
\text { contractors, designers and manufacturers on a project }\end{array}$ & $\begin{array}{l}\text { - Training Handbook } \\
\text { - Classroom Presentation } \\
\text { - Interactive Assignments }\end{array}$ & $\begin{array}{l}\text { - Instructor presents in a classroom } \\
\text { setting } \\
\text { - Participants are broken into } \\
\text { groups to discuss and prepare for } \\
\text { assessments }\end{array}$ & $\begin{array}{l}\text { - } 2.1 \text { Clarify vocabulary and } \\
\text { symbols } \\
\text { - } 3.2 . \text { Highlight patterns, critical } \\
\text { features, big ideas, and } \\
\text { relationships }\end{array}$ & $\begin{array}{l}\text { - Groups to present information } \\
\text { verbally, through text, or graphically }\end{array}$ \\
\hline
\end{tabular}




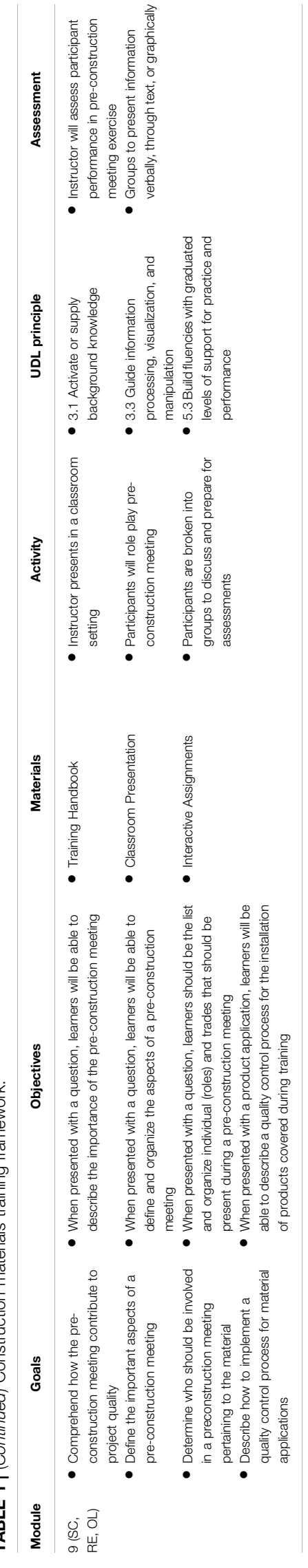

\section{Module 9: Pre-Construction Meeting}

The purpose of this module is to provide an understanding of the importance of pre-constructions meeting for a material application. Participants will learn the components of preconstruction meeting, who should be involved and how to use the pre-construction meeting to assure installation quality.

Under the 70:20:10 philosophy, this module is classified as a challenging assignment, because of the need to engage in a mock pre-construction meeting. Bloom's Taxonomy terms such as "define", "describe", and "organize" in the "Remember", "Understand", and "Create" categories, respectively appear most frequently in the goals and objectives, denoting the necessity to remember, comprehend, and perform utilizing the information gathered. The UDL principles noted are designed to provide options for comprehension, expression, and communication.

The assumptions of this module are SC, RE, and OL. Participants will be required to manage a trial pre-construction meeting pertaining to the materials addressed during training. Throughout this process they will have to direct themselves and use the knowledge that they have acquired during the training process. Feedback will be given to them following observations from the instructor. The experience that participants have both before and during training again has a vital role. They will have to call upon not only technical information acquired during training, but also the soft skills necessary to manage expectations of product installation quality, performance, and scheduling. The expectation is that participants will be involved in construction projects involving the materials that they have just been trained to install very soon after training. This provides the connection to the orientation to learning assumption as they should feel the exercise's immediate application.

\section{Assessment}

The Taxonomy of Educational Objectives (Bloom 1956), revised by Anderson and Krathwohl (2001) divides education into six categories of processes necessary for effective education. These processes are remember, understand, apply, analyze, evaluate, and create. These categories pertain to the cognitive domain of the taxonomy. The affective and psychomotor domains are not used as part of this assessment. This taxonomy was designed to be a sequential process. For example, one must remember before understanding and application take place. Bloom's Taxonomy, as it is regularly known, is used in the formulation of this framework as a method of assessing the fulfillment of each category of processes while simultaneously providing an application benchmark for the educational theory used throughout this paper. Terms have been attributed to each of the six categories that link to each category in the taxonomy. A quantification of Bloom's Taxonomy is done by enumerating the instances that any of terms contained in each of the six categories occur within an educational framework or instructional design. Certain terms in Bloom's Taxonomy fall under more than one category. To avoid a duplication of counting the terms, the duplicated terms should either be avoided or the context in which they are used should be taken into consideration before categorizing. Bloom's Taxonomy categories and associated 


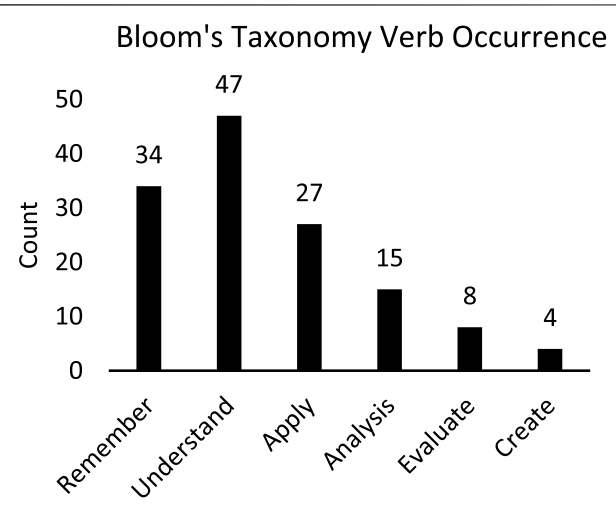

FIGURE 2 | Bloom's taxonomy frequency by verb and category of training goals.

verbs used to identify and quantify training learning objectives are provided in the Appendix.

Autonomous counting, used to generate numbers of occurrences that stand on their own merit (Hannah and Lautsch 2011), was used to determine how closely the training goals and objectives followed Bloom's Taxonomy guidelines, a method which (Horner et al., 2011) implemented to evaluate the potential effectiveness of lesson plans designed for college courses. NVivo 12, a qualitative data analysis software, was used to identify the frequency of occurrence of each verb by level. The verbs were grouped into their corresponding Taxonomy categories and the distribution was assessed.

\section{RESULTS}

This section presents the linkages from educational theory to proposed modules established in the previous section. The framework is summarized by categorizing the modules into lesson segments involving construction material information, project execution functions as they relate to the construction materials, and pre-construction activities so that the main points of the overall framework can be extracted, and ease of adoption can be achieved. The module template is then presented in a goals and objectives format so that material manufacturers can best and test the training proposal. This is followed by an assessment of training goals using Bloom's Taxonomy as the primary tool of assessment detailed previously.

\section{Framework Construction}

Figure 1 summarizes the overall framework by grouping the main lesson segments so that construction training designers may more easily adopt and modify the framework to best suite training participant needs.

The modules provide examples of goals and objectives written based on goal setting theory and SMART objective writing that provide direction and benchmarks for each module. At the conclusion of each module participants will be able to meet all objectives to ensure that the purpose of the
TABLE 2 | Bloom's taxonomy frequency by verb and category of training goals.

\begin{tabular}{|c|c|c|c|c|c|c|c|c|c|c|}
\hline Module & 1 & 2 & 3 & 4 & 5 & 6 & 7 & 8 & 9 & Total \\
\hline Remember & & & & & & & & & & - \\
\hline Define & & & & & & & & 2 & 2 & 4 \\
\hline Identify & 3 & 3 & 1 & 3 & & 4 & 2 & 1 & & 17 \\
\hline List & 1 & & & & & & & & 1 & 2 \\
\hline Name & & & & & & & & 1 & & 1 \\
\hline Relate & 1 & & & 1 & 1 & 1 & & & & 4 \\
\hline Select & & & 1 & & 4 & & & & & 5 \\
\hline State & & & & & & & 1 & & & 1 \\
\hline Understand & & & & & & & & & & - \\
\hline Cite & 1 & & & & & & & & & 1 \\
\hline Comprehend & 1 & 2 & & 2 & & 3 & 3 & 2 & 1 & 14 \\
\hline Describe & 1 & & & & & & & 3 & 3 & 7 \\
\hline Discuss & 3 & & & & 2 & 1 & & 1 & & 7 \\
\hline Identify & 3 & 3 & 1 & 3 & & 4 & 2 & 1 & & 17 \\
\hline Suggest & & & & & 1 & & & & & 1 \\
\hline Apply & & & & & & & & & & - \\
\hline Construct & & & & & & & & & & 1 \\
\hline Demonstrate & & 1 & & 1 & & & & & & 2 \\
\hline Document & & & 1 & & & & & 3 & & 4 \\
\hline Give examples & & 2 & & 1 & & 1 & 1 & 1 & & 6 \\
\hline Practice & & & & & 1 & & & & & 1 \\
\hline Show & & & & & 3 & & & & & 3 \\
\hline Use & & 3 & 2 & 2 & 1 & & 2 & & & 10 \\
\hline Analysis & & & & & & & & & & - \\
\hline Determine & & & & & & & & 1 & 1 & 2 \\
\hline Relate & 1 & & & 1 & 1 & 1 & & & & 4 \\
\hline Solve & & & 1 & & 2 & & & & & 3 \\
\hline Test & & & & & & 2 & 2 & 2 & & 6 \\
\hline Evaluate & & & & & & & & & & - \\
\hline Assess & & & & & & & & 1 & & 1 \\
\hline Evaluate & & & & 1 & & & 1 & & & 2 \\
\hline Select & & & 1 & & 4 & & & & & 5 \\
\hline Create & & & & & & & & & & - \\
\hline Organize & & & & & & & & & 2 & 2 \\
\hline Perform & & & & & & 2 & & & & 2 \\
\hline Total & & & & & & & & & & 135 \\
\hline
\end{tabular}

training has been met and the required knowledge has been disseminated in an effective fashion. Table 1 outlines the goals, objectives, materials needed, activities, UDL principles, and assessments used for all modules.

\section{Assessment}

This section assesses the training framework by using the verb categories of Bloom's Taxonomy found in the Appendix. Figure 2 presents the results of this assessment graphically and Table 2 presents them explicitly. The connection of the framework to the principles of the Andragogy, The 70:20:10 Philosophy, and UDL are also presented.

Of the 135 terms counted in the training goals, $108(80 \%)$ focus on LOTS. The results show the focus on LOTS corroborates the focus on introductory participants. Should a training be designed where it is known that participants have a basic understanding of the subject matter, HOTS should be the focus.

Table 3 summarizes the connection from each module to the corresponding assumption(s) of andragogy that are presented in the Framework Construction section. The Role of Experience (RE) assumption of andragogy occurs most often in this study because the target audience of this framework is current industry 
TABLE 3 | Connection of training modules to andragogy.

\begin{tabular}{|c|c|c|c|c|c|c|c|}
\hline \multirow[b]{2}{*}{ Training module } & \multicolumn{6}{|c|}{ Assumptions of andragogy } & \multirow[t]{2}{*}{ Total } \\
\hline & sc & RE & $\mathbf{R L}$ & OL & IM & NK & \\
\hline Product Chemistry & & $x$ & & & & $x$ & 2 \\
\hline Understanding Product Portfolio & & $x$ & $x$ & & $x$ & & 3 \\
\hline Material Selection & & & & & & $x$ & 1 \\
\hline Installation Techniques & $x$ & & & $x$ & & & 2 \\
\hline Group Scenario Activity & & $x$ & & $x$ & & $x$ & 3 \\
\hline Troubleshooting & & $x$ & & & & $x$ & 2 \\
\hline Hands - On Demonstration Assessment & & $x$ & & & $x$ & & 2 \\
\hline Product Specifications & & $x$ & $x$ & & & & 2 \\
\hline Pre-Construction Meeting & $x$ & $x$ & & $x$ & & & 3 \\
\hline Total & 2 & 7 & 2 & 3 & 2 & 4 & 20 \\
\hline
\end{tabular}

TABLE 4 | Connection of training modules to the 70:20:10 principle.

\begin{tabular}{lccc} 
& \multicolumn{3}{c}{ 70:20:10 Principle } \\
\cline { 2 - 4 } Training Module & Experiential & Social & Formal \\
\hline Product Chemistry & & & $\times$ \\
Understanding Product Portfolio & $\times$ & & \\
Material Selection & $\times$ & & \\
Installation Techniques & $x$ & & \\
Group Scenario Activity & & $x$ & \\
Troubleshooting & $\times$ & & \\
Hands - On Demonstration Assessment & $\times$ & & \\
Product Specifications & & $x$ & \\
Pre-Construction Meeting & $\times$ & & 1 \\
Total & 6 & 2 & 1
\end{tabular}

TABLE 5 | Connection of training modules to UDL principles.

\begin{tabular}{lccc}
\hline & \multicolumn{3}{c}{ UDL principle multiple means of } \\
\cline { 2 - 4 } Training module & Representation & $\begin{array}{c}\text { Action and } \\
\text { expression }\end{array}$ & Engagement \\
\hline Product Chemistry & 4 & & \\
Understanding Product & 2 & & \\
Portfolio & 2 & 1 & 1 \\
Material Selection & 3 & & 1 \\
Installation Techniques & 1 & & 1 \\
Group Scenario Activity & 3 & & \\
Troubleshooting & 2 & & \\
Hands-On & & & \\
Demonstration & 2 & & \\
Assessment & 2 & & \\
Product Specifications & 21 & & \\
Pre-Construction & & & \\
Meeting & & & \\
Total & & & \\
& & & \\
\end{tabular}

professionals that possess work experience. The RE assumption is referenced seven times in the framework while all other assumptions are referenced two to four times. However, this study's framework is for an introductory level of construction professionals in terms of the presumed exposure to construction materials involved in the training. The Readiness to Learn (RL) and Internal Motivation (IM) occur less often than all other categories because it is often the case that these types of training programs are made mandatory by employers. To compensate for this, the focus is on the remaining andragogical learning assumptions.

Table 4 details the classification of each module under the 70: 20:10 philosophy. As previously noted, $70 \%$ is of learning is derived through challenging assignments (experiential), 20\% occurs through developmental relationships (social), and 10\% occurs through formal training and coursework (formal). The table shows that $6 / 9(67 \%)$ of the modules are classified as experiential, $2 / 9(22 \%)$ are classified as social, and $1 / 9$ (11\%) is classified as formal, closely adhering to the recommended model.

Table 5 summarizes the connection from each module to the corresponding UDL Principles. Providing multiple means of representation occurs in 21 out of 26 UDL level references $(81 \%)$ because of the importance of delivering the information to trainees in multiple formats. The Action and Expression category is noted twice in instances where there is a demonstration or installation activity in the module. The Engagement category is referenced three times in modules where it is necessary to interact with a group or directly with an instructor to provide trainees with multiple options for conveying their thoughts.

\section{CONCLUSION}

This study created a framework for training construction industry workers on the subject of construction materials. This framework incorporates andragogy, UDL principles, and the 70:20:10 philosophy. Corresponding linkages to andragogy and UDL principles are established to each of the nine modules that collectively makeup the framework presented. This culminates into a proposed template of goals and objectives that can be applied by construction material manufacturers interested in training construction stakeholders. Bloom's Taxonomy is used to assess the framework presented to determine how closely the verbs correspond with the assumed audience. The focus on LOTS confirm that the training framework presented is suitable for introductory participants with $80 \%$ of the verbs falling into the LOTS category. The specific contributions of this research are for the first time: UDL, andragogy, and 70:20: 
10 principles have been linked to construction workforce training, Bloom's Taxonomy was used as an assessment method to evaluate a proposed construction workforce training, and education theory has been embedded into a training proposed specifically for construction material manufacturers.

Through this study and the developed framework, construction material manufacturers are able to tailor material training programs for their products to better serve installers using these principles and theories for the first time; which in turn increases the sustainability of infrastructure leading to project success and lower cost in the long term. Whereas there is precedence in the literature for a presentation of construction training concepts and results, this study presents a detailed instructional design that material manufacturers can replicate. An opportunity exists to test the efficacy of the proposed framework by training construction stakeholders using this framework. A similar opportunity exists to develop a training framework using similar methodologies for participants who are

\section{REFERENCES}

Abbas, A., Din, Z. U., and Farooqui, R. (2016). Achieving Greater Project Success \& Profitability through Pre-construction Planning: A Case-Based Study. Proced. Eng. 145, 804-811. doi:10.1016/j.proeng.2016.04.105

Abudayyeh, O., Russell, J., Johnston, D., and Rowings, J. (2000). Construction Engineering and Management Undergraduate Education. J. Constr. Eng. Manage. 126 (3), 169-175. doi:10.1061/(ASCE)0733-9364(2000)126:3(169)

Anderson, L. W., and Krathwohl, D. R. (2001). A Taxonomy for Learning, Teaching, and Assessing: A Revision of Bloom's Taxonomy of Educational Objectives. New York: Longman.

Antonis, K., Daradoumis, T., Papadakis, S., and Simos, C. (2011). Evaluation of the Effectiveness of a Web-Based Learning Design for Adult Computer Science Courses. IEEE Trans. Educ. 54 (3), 374-380. doi:10.1109/TE.2010.2060263

Arditi, D., and Gunaydin, H. M. (1997). Total Quality Management in the Construction Process. Int. J. Project Manag. 15, 235-243. doi:10.1016/ S0263-7863(96)00076-2

Ariga, A., and Lleras, A. (2011). Brief and Rare Mental "Breaks” Keep You Focused: Deactivation and Reactivation of Task Goals Preempt Vigilance Decrements. Cognition 118, 439-443. doi:10.1016/j.cognition.2010.12.007

Bena, A., Berchialla, P., Coffano, M. E., Debernardi, M. L., and Icardi, L. G. (2009). Effectiveness of the Training Program for Workers at Construction Sites of the High-Speed Railway Line between Torino and Novara: Impact on Injury Rates. Am. J. Ind. Med. 52 (12), 965-972. doi:10.1002/ajim.20770

Birzer, M. L. (2003). The Theory of Andragogy Applied to Police Training. Policing 26 (1), 29-42. doi:10.1108/13639510310460288

Bloom, B. S. (1956). Taxonomy of Educational Objectives. New York, D. McKay: The Classification of Educational Goals.

Chunlin, Y. (2017). A Case Study on the Factors Affecting Chinese Adult Students' English Acquisition in a Blended Learning Environment. Int. J. Cont. Eng. Edu. Lifelong Learn. 27 (1/2), 22-44.

Churches, A. (2008). Bloom's Taxonomy Blooms Digitally. Tech. Learn. 1, 1-6.

Eggerth, D. E., Keller, B. M., Cunningham, T. R., and Flynn, M. A. (2018). Evaluation of Toolbox Safety Training in Construction: The Impact of Narratives. Am. J. Ind. Med. 61 (12), 997-1004. doi:10.1002/ajim.22919

Forcada, N., Macarulla, M., Gangolells, M., and Casals, M. (2014). Assessment of Construction Defects in Residential Buildings in Spain. Building Res. Inf. 42 (5), 629-640. doi:10.1080/09613218.2014.922266

Gaikwad, S. S., and Bharathi, S. V. (2018). An Exploratory Study on the Application of Multiple Intelligences to MBA Andragogy with Particular Reference to ERPControlling Configuration Course. Int. J. Inf. Commun. Tech. Edu. 14 (1), 58-72. doi:10.4018/IJICTE.2018010105 assumed to be more advanced where the focus of the training is terminology in the HOTS category.

\section{DATA AVAILABILITY STATEMENT}

The original contributions presented in the study are included in the article/Supplementary Material, further inquiries can be directed to the corresponding author.

\section{AUTHOR CONTRIBUTIONS}

HJ conducted the literature review, collected and analyzed and developed the initial text. CF provided original ideas and advice on the overall project methodology and edited the text. $\mathrm{CB}$ proposed the research methodology and provided the conceptual design of this research. IN, CP, and YZ edited the text and provided regular feedback and guidance.

Goulding, J., Nadim, W., Petridis, P., and Alshawi, M. (2012). Construction Industry Offsite Production: A Virtual Reality Interactive Training Environment Prototype. Adv. Eng. Inform. 26 (1), 103-116. doi:10.1016/j.aei.2011.09.004

Hammond, J. (2001). Scaffolding: Teaching and Learning in Language and Literacy Education. Newtown, New South Wales: ERIC.

Hannah, D. R., and Lautsch, B. A. (2011). Counting in Qualitative Research: Why to Conduct it, when to Avoid it, and when to Closet it. J. Manag. Inq. 20, 14-22. doi:10.1177/1056492610375988

Harris, C. M. (2006). Dictionary of Architecture and Construction. New York: McGraw-Hill.

Hitchcock, C. (2001). Balanced Instructional Support and Challenge in Universally Designed Learning Environments. J. Spec. Educ. Technol. 16 (4), 23-30. doi:10.1177/016264340101600404

Horner, R., Závodská, A., and Rushing, J. (2011). How Challenging? Using Bloom's Taxonomy to Assess Learning Objectives in A Degree Completion Program. Tlc 2, 47-52. doi:10.19030/tlc.v2i3.1785

Hosseinian, S. S., and Jabbarani, Z. (2012). Major Theories of Construction Accident Causation Models : a Literature Review. Int. J. Adv. Eng. Tech. 4, 1

Jadallah, H., Friedland, C. J., Nahmens, I., Pecquet, C., Berryman, C., and Zhu, Y. (2021a). Construction Industry Training Assessment Framework. Front. Built Environ. 7 (117), 1. doi:10.3389/fbuil.2021.678366

Jadallah, H., Friedland, C. J., Nahmens, I., Pecquet, C., Berryman, C., and Zhu, Y. (2021b). Educational Theory-Integrated Construction Industry Training: State-OfThe-Art Review. Front. Built Environ. 7 (84), 1. doi:10.3389/fbuil.2021.635978

Jarkas, A. M. (2010). Critical Investigation into the Applicability of the Learning Curve Theory to Rebar Fixing Labor Productivity. J. Constr. Eng. Manage. 136 (12), 1279-1288. doi:10.1061/(ASCE)CO.1943-7862.0000236

Johnston, S. C., and Castine, E. (2019). UDL in Apprenticeships and Career Training Programs that Serve Youth with Untapped Talent. Transforming Higher Education through Universal Design for Learning: An International Perspective. Taylor \& Francis, 131-158. doi:10.4324/9781351132077-9

Joo Hyoung, L., McCullouch, B. G., and Luh-Maan, C. (2008). Macrolevel and Microlevel Frameworks of Experiential Learning Theory in Construction Engineering Education. J. Prof. Issues Eng. Edu. Pract. 134 (2), 158-164. doi:10.1061/(ASCE)1052-3928(2008)134:2(158)

Karimi, H., Taylor, T. R. B., Dadi, G. B., Goodrum, P. M., and Srinivasan, C. (2018). Impact of Skilled Labor Availability on Construction Project Cost Performance. J. construction Eng. Manag. 144 (7), 1. doi:10.1061/(ASCE)CO.19437862.0001512

Killingsworth, J., and Grosskopf, K. R. (2013). syNErgy. Adult Learn. 24 (3), 95-103. doi:10.1177/1045159513489111

Knowles, M. S. (1980). The Modern Practice of Adult Education: From Pedagogy to Andragogy. Conn, Follett: Wilton. 
Li, H., Lu, M., Chan, G., and Skitmore, M. (2015). Proactive Training System for Safe and Efficient Precast Installation. Automation in Construction 49, 163-174. doi:10.1016/j.autcon.2014.10.010

Lin, K.-Y., Lee, W., Azari, R., and Migliaccio, G. C. (2018). Training of Low-Literacy and Low-English-Proficiency Hispanic Workers on Construction Fall Fatality. J. Manage. Eng. 34 (2), 05017009. doi:10.1061/(ASCE)ME.1943-5479.0000573

Locke, E. A., and Latham, G. P. (2002). Building a Practically Useful Theory of Goal Setting and Task Motivation: A 35-year Odyssey. Am. Psychol. 57 (9), 705-717. doi:10.1037/0003-066X.57.9.705

McCall, M. W., Lombardo, M. M., and Morrison, A. M. (1988). The Lessons of Experience: How Successful Executives Develop on the Job. Hum. Resource Manag. 27 (3), 359.

Mehmood, Z., Haneef, I., and Udrea, F. (2018). Material Selection for Microelectro-mechanical-systems (MEMS) Using Ashby's Approach. Mater. Des. 157, 412-430. doi:10.1016/j.matdes.2018.07.058

Merriam, S. B., Caffarella, R. S., and Baumgartner, L. (2007). Learning in Adulthood: A Comprehensive Guide. San Francisco, Calif: John Wiley \& Sons; Jossey-Bass.

Mills, A., Love, P. E., and Williams, P. (2009). Defect Costs in Residential Construction. J. Constr. Eng. Manage. 135 (1), 12-16. doi:10.1061/(ASCE) 0733-9364(2009)135:1(12)

Mohamad, N., Abdul Rahman, H., M. Tawil, I., and Mohd Tawil, N. (2015). Ethics Education and Training for Construction Professionals in Malaysia. Ass 11, 1. doi:10.5539/ass.v11n4p55

Munyimi, T. F. (2019). The Role of Procurement Specifications in Curbing Wrong Deliveries of Construction Materials in the Construction Sector in Zimbabwe. Cogent Eng. 6 (1), 1. doi:10.1080/23311916.2019.1631542

Nikolova, I., and Collis, B. (1998). Flexible Learning and Design of Instruction. $\mathrm{Br}$. J. Educ. Tech. 29 (1), 59-72. doi:10.1111/1467-8535.00046

Nuthall, G., and Alton-Lee, A. (1995). Assessing Classroom Learning: How Students Use Their Knowledge and Experience to Answer Classroom Achievement Test Questions in Science and Social Studies. Am. Educ. Res. J. 32 (1), 185-223. doi:10.3102/00028312032001185

Orkwis, R. (2003). Universally Designed Instruction. ERIC/OSEP Digest.

Padwa, L., Kelly, A. M., and Sheppard, K. (2019). Chemistry Teacher Isolation, Contextual Characteristics, and Student Performance. J. Chem. Educ. 96, 2383-2392. doi:10.1021/acs.jchemed.9b00392

Parkinson, T. M., Force, J. E., and Smith, J. K. (2003). Hands-on Learning: Its Effectiveness in Teaching the Public about Wildland Fire. J. For. 101 (7), 21-26. doi:10.1093/jof/101.7.21

Rose, D., and Dolan, B. (2000). Universal Design for Learning. J. Spec. Educ. Technol. 15 (4), 47-51. doi:10.1177/016264340001500407

Rowe, D. A., Mazzotti, V. L., Ingram, A., and Lee, S. (2017). Effects of GoalSetting Instruction on Academic Engagement for Students at Risk. Career
Dev. Transit. Exceptional Individuals 40 (1), 25-35. doi:10.1177/ 2165143416678175

Russell, J. S., Hanna, A., Bank, L. C., and Shapira, A. (2007). Education in Construction Engineering and Management Built on Tradition: Blueprint for Tomorrow. J. Constr. Eng. Manage. 133 (9), 661-668. doi:10.1061/ (ASCE)0733-9364(2007)133:9(661)

Sundqvist, J., Lindahl, B. G., and Goran, L. (2012). Cooperation in the Building Sector between Building Material Manufacturers and Contractors to Develop Products. Ceb 7 (2), 45-53. doi:10.5130/AJCEB.v7i2.2990

Tatum, C. B. (2011). Core Elements of Construction Engineering Knowledge for Project and Career Success. J. Constr. Eng. Manage. 137 (10), 745-750. doi:10.1061/(ASCE)CO.1943-7862.0000306

Tatum, C. B. (2018). Learning Construction Engineering: Why, what, and How? J. Constr. Eng. Manage. 144 (3), 04018004. doi:10.1061/(ASCE)CO.19437862.0001436

Thorsteinsson, G., and Page, T. (2018). The Standing of Hands-On Learning in Education. J. Educ. Psychol. 11 (3), 1-11.

Wei, B., and Li, X. (2017). Exploring Science Teachers' Perceptions of Experimentation: Implications for Restructuring School Practical Work. Int. J. Sci. Edu. 39 (13), 1775-1794. doi:10.1080/09500693.2017.1351650

Wood, D., Bruner, J. S., and Ross, G. (1976). The Role of Tutoring in Problem Solving. J. Child. Psychol. Psychiat 17 (2), 89-100. doi:10.1111/j.14697610.1976.tb00381.x

Ziębacz, I., and Moraru, R. I. (2017). The Quality of Human Capital and the Risk in Terms of Evolutionary Psychology. Qual. - Access Success 18, 51-56.

Conflict of Interest: The authors declare that the research was conducted in the absence of any commercial or financial relationships that could be construed as a potential conflict of interest.

Publisher's Note: All claims expressed in this article are solely those of the authors and do not necessarily represent those of their affiliated organizations, or those of the publisher, the editors and the reviewers. Any product that may be evaluated in this article, or claim that may be made by its manufacturer, is not guaranteed or endorsed by the publisher.

Copyright (c) 2022 Jadallah, Friedland, Nahmens, Pecquet, Berryman and Zhu. This is an open-access article distributed under the terms of the Creative Commons Attribution License (CC BY). The use, distribution or reproduction in other forums is permitted, provided the original author(s) and the copyright owner(s) are credited and that the original publication in this journal is cited, in accordance with accepted academic practice. No use, distribution or reproduction is permitted which does not comply with these terms. 
APPENDIX 1

Bloom's Taxonomy Categories and Associated Verbs (Anderson and Krathwohl 2001).

\begin{tabular}{|c|c|c|c|c|c|}
\hline Remember & Understand & Apply & Analyze & Evaluate & Create \\
\hline Choose & Arrange & Apply & Analyze & Appraise & Arrange \\
\hline Define & Cite & Chart & Calculate & Assess & Assemble \\
\hline Enumerate & Classify & Collect & Categorize & Choose & Collect \\
\hline Identify & Comprehend & Compute & Compare & Compare & Compose \\
\hline Indicate & Describe & Construct & Contrast & Contrast & Construct \\
\hline Know & Discuss & Demonstrate & Criticize & Criticize & Create \\
\hline Label & Explain & Document & Debate & Critique & Design \\
\hline List & Explore & Dramatize & Detect & Decide & Formulate \\
\hline Match & Express & Employ & Determine & Defend & Generate \\
\hline Memorize & Extrapolate & Give examples & Diagram & Estimate & Integrate \\
\hline Name & Generalize & Interpret & Differentiate & Evaluate & Organize \\
\hline Omit & Identify & Investigate & Disassemble & Grade & Perform \\
\hline Recall & Indicate & Operate & Distinguish & Judge & Plan \\
\hline Record & Infer & Practice & Examine & Justify & Prepare \\
\hline Relate & Interpret & Predict & Experiment & Measure & Produce \\
\hline Repeat & Judge & Schedule & Inspect & Rate & Propose \\
\hline Reproduce & Locate & Shop & Inventory & Reframe & Set up \\
\hline Select & Manage & Show & Justify & Revise & Synthesize \\
\hline State & Match & Sketch & Question & Score & \\
\hline \multirow[t]{12}{*}{ Underline } & Paraphrase & Transfer & Relate & Select & \\
\hline & Recognize & Translate & Separate & Value & \\
\hline & Report & Use & Solve & Weigh & \\
\hline & Represent & & Subdivide & & \\
\hline & Restate & & Test & & \\
\hline & Review & & & & \\
\hline & Show & & & & \\
\hline & Suggest & & & & \\
\hline & Summarize & & & & \\
\hline & Tell & & & & \\
\hline & Trace & & & & \\
\hline & Translate & & & & \\
\hline
\end{tabular}

